International Journal of Advanced Chemistry, $8(1)(2020) 128-140$
International Journal of Advanced Chemistry
Website: www.sciencepubco.com/index.php/IJAC
Research paper

\title{
Comparative viscometric study of pure and acetylated gum Arabic using different plot methods
}

\author{
Alhassan S. I ${ }^{1}$, Sule S. Y ${ }^{1}$, Murtala $R^{1}$, Rasheed H. I ${ }^{2}$, Baso A. A ${ }^{1}$, Sheshe F. A ${ }^{2}$, Jafar S. C ${ }^{3}$ \\ ${ }^{1}$ Kano University of Science and Technology, Wudil, Kano, Nigeria. \\ ${ }^{2}$ Bayero University Kano, Nigeria \\ ${ }^{3}$ Ahmadu Bello University,Zaria, Nigeria \\ *Corresponding author E-mail:saniidris2012@gmail.com
}

\begin{abstract}
Acetylation of gum Arabic was achieved using acetic anhydride as solvent. The ester group formed was confirmed by FTIR spectra having absorption band of $750 \mathrm{~cm}-1-700 \mathrm{~cm}-1$. Viscometric study of the pure and acetylated samples was carried out. Relative viscosity of acetylated gum was found to be higher than that of the pure gum. Intrinsic viscosity was determined for the two samples using different plot methods taking Huggin's plot as standard. The intrinsic viscosity was found to be $86.43 \mathrm{~cm} 3 / \mathrm{g}$ and $64.59 \mathrm{~cm} 3 / \mathrm{g}$ for acetylated and pure gum arabic respectively. Relative errors of other methods for the two samples was compared to that of Huggins and the plots that are most comparable to Huggins with relative errors less than 5\% are; Martin, Lyon-Tobolsky, Staudinger-Heuer, Maron-Reznik and our proposed method. The proposed method which was a modification of the Kreiser method gave relative error less than $2 \%$, for both pure and modified gum. Whereas the Kreiser method gave relative error greater than $15 \%$ for both methods. The critical concentration for the samples was found to be $0.0116 \mathrm{~g} / \mathrm{cm} 3$ and $0.0155 \mathrm{~g} / \mathrm{cm} 3$ for acetylated and pure gum respectively. This shows that there was no moleculemolecule entanglements during viscosity measurements.
\end{abstract}

Keywords: Intrinsic Viscosity; Acetylation; Gum Arabic.

\section{Introduction}

Gum Arabic exudate is gummy, dry and edible. It is usually obtained from stems and branches of Acacia senegal and Acacia seyal that have high content of non-viscous soluble fibre (Williams, 2000). It is a salt of complex polysaccharides that is neutral or slightly acidic in nature, containing $\mathrm{Ca}^{2+}, \mathrm{Mg}^{2+}$ and $\mathrm{K}^{+}$. Its most distinguishing character among other gums is that it is extremely soluble in water. The exudate is found mainly in unhealthy trees that are affected by diseases, drought or poor nutrition. The gum comes out through wounds carved in the bark of the tree in liquid drops, which then becomes hard with time. The tree's taxonomic classification is genus; Acacia, subfamily; Mimosoidene, family; leguminosae (Smolinske, 1992).

The gum itself comprise of different materials but may be separated in to three major parts. $88.4 \%$ of the gum is arabinogalactan with $0.35 \%$ protein content and has molecular weight of $3.8 \times 10^{5} \mathrm{Da} .10 .4 \%$ is arabinogalactan protein with $11.4 \%$ protein and $4.5 \times 10^{6} \mathrm{Da}$ molecular weight. The third part (1.2\%) is glycoprotein with $47.3 \%$ protein content with $2.5 \times 10^{5}$ Da molecular weight (Randell et al., 1989).

Gums obtained from acacia species have high molecular weight (Baldein et al, 1999), are used as gels and thickeners (Savary et al., 2009), have emulsifying properties (Huang et al, 2001; Islam et al., 1997), stabilization properties (Dickinson, 2001) and can be used for microencapsulation (Renard et al, 2002). It can also be used in pharmaceutical industries ((Nasir et al, 2010), has biotechnology applications (Ben-Zion and Nussinovitch, 1997) and as an adhesive (Cochrane, 1996)

Viscometry is an analytical method used to characterize polymer properties in dilute solutions. It allows fast and very simple way of determining structure, polymer concentration, polymer chain dimensions, molecular weight, and other thermodynamic properties of a polymer in solution (Kulicke and Clasen 2004).

Viscosity can be defined as resistance to flow, reflecting the frictional forces of all molecules (of both solute and solvent) present in solution.

Capillary viscometers commonly measure the kinematic viscosity, which is the ratio of viscosity to the density of solution. To measure viscosity using a capillary viscometer, a certain amount of the polymer solution is placed in the capillary that has two marks at different levels. The flow time for the solution to pass between two lines marked in the viscometer is proportional to the kinematic viscosity of the solution.

The viscosity of a solution is expressed as the sum of viscosity of the dissolved polymer and the viscosity of the solvent (Kulicke and Clasen 2004). Relative viscosity therefore, is defined as the ratio of solution viscosity to solvent viscosity (Kulicke and Clasen 2004). In 
order to describe an incremental change in solvent viscosity upon dissolution of a polymer, the term specific viscosity is often used. The reduced viscosity is defined as the specific viscosity divided by the concentration of the polymer.

In order to obtain the intrinsic viscosity of a polymer, the reduced viscosity data is extrapolated to zero polymer concentration. It should be noted that the units of intrinsic viscosity and reduced viscosity are "volume/mass". The intrinsic viscosity can also be treated as the natural ability of a polymer to increase the viscosity of a solution (Huggins 1942). Therefore, the intrinsic viscosity is dependent on the shape, size and molecular weight of a polymer.

Dilute solution of a polymer can be defined as such a solution in which the polymer macromolecules are sufficiently far apart from one another so that their mutual interactions are eliminated and only polymer-solvent interactions take place.

The most important requirement for reliable intrinsic viscosity measurement is that the tested solution must be sufficiently dilute to eliminate polymer-polymer inter-chain interactions, so only polymer-solvent interactions and perhaps some intra-chain forces govern the size and conformation of individual polymer chains. At this state, the solution is said to be ideal-dilute, and the polymer molecule only interacts with the solvent. Therefore, the intrinsic viscosity of a polymer is only defined by the dimension of this single coil in solution (Kulicke and Clasen 2004). As the concentration of a polymer is gradually increased, spaces between molecules is reduced, and the molecules become more compacted producing a change in flow behavior. In diluted solutions, polymer coils must be spatially separated to prevent the formation of mechanical entanglements between the polymer chains. This process takes place at specific concentration called the critical concentration $\left(\mathrm{C}_{*}\right)$. Above this concentration, flow behavior of polymer coils is dominated by intermolecular interactions, and at concentrations below, the flow behavior is mainly due to polymer-solvent interaction. Therefore volume occupied by polymer coils is inversely proportional to the critical concentration.

Truly dilute polymer solutions are Newtonian while the presence of entanglements usually leads to non-Newtonian effects, such as timedependent flow or visco-elasticity (Robinson et al. 1982). Lovell (1989) argued that in the most general case the transition concentration is $\mathrm{C}_{*} \approx \frac{1}{[\eta]}$ at to ensure truly dilute solution conditions.

Industries that use gums as raw materials are in continuous search for better gums with improved physicochemical characteristics, higher quality and lower cost of production. In this work, we seek to determine the feasibility of obtaining intrinsic viscosity of pure and acetylated (modified) gum Arabic using different equations, and also compare their viscosity average molecular weights.

\section{Materials and methods}

\subsection{Materials}

Arabic gum was obtain from Malam Musa Maiunguwa at kurmi Market. Ethanol, Acetic Anhydride and diethyl ether were obtained from BDH. Some of the glassware used are; beakers, pipettes, majoring cylinder, volumetric flasks. The equipment used are; clinical thermometer, Ostwald viscometer, constant temperature magnetic stirrer, and analytical weighing balance.

\subsubsection{Sample collection}

The raw exudate of Acacia Senegal gums was bought from Kurmi Market in Kano State. Malam Musa Maiunguwa assured us that the gum was from Acacia senegal which was obtained from Acacia tree in one of the bushes in Sokoto State, Nigeria.

\subsubsection{Sample identification}

The exudate sample of the gum was taken to the Department of forestry, fishery and wild life in the faculty of Agricultural science at Kano University of Science and Technology Wudil for further identification, and was identified and certified as Acacia senegal gum.

\subsection{Methods}

\subsubsection{Sample purification}

Impurities such as pieces of tree bark were removed by hand, and the gum was crushed to obtain smaller chunks. The gum then hydrated in distilled water for three days. The mucilage obtained was forced to drain through a calico cloth and 95\% ethanol was used for precipitation of the gum. The precipitate was washed with diethyl ether, dried, powdered and stored in a desiccator for further use (Oluyemisi et al, 2010).

\subsubsection{Sample modification}

Acetic anhydride was used for this modification. $10 \mathrm{~g}$ of the gum was dissolved in $50 \mathrm{ml}$ of distilled water. This makes $20 \% \mathrm{w} / \mathrm{v}$ concentration of the mixture. $5 \mathrm{~g}$ of acetic anhydride corresponding to $50 \%$ by weight of dry gum was added to the mixture. The mixture was heated at $70^{\circ} \mathrm{C}$ for three hours, allowed to cool, dry and was then powdered (Sowunmi, 1990).

\subsubsection{Preparation of gum solutions}

Pure and modified gum samples were dissolved in distilled water to obtain $0.1 \%, 0.2 \%, 0.3 \%, 0.4 \%$ and $0.5 \%$ w/v concentrations. Solutions were gently stirred and slightly heated to obtain a uniform solution. Samples were then allowed to cool overnight.

\subsubsection{Density measurement}

Measurement of densities was carried out with the use of relative density bottles. The R.D bottle was first washed with chromic acid, rinsed with distilled water and then with alcohol, allowed to dry, and then weighted. It was then filled with distilled water and stoppered. The R.D bottle was then weighted again. Water is then removed, the bottle was washed again with alcohol and dried. It was thereafter filled with experimental liquid as before and weighted again. The density of the experimental solution was determined using the formula below.

$\mathrm{d}_{1}=\frac{\mathrm{w}_{3}-\mathrm{w}_{1}}{\mathrm{w}_{2}-\mathrm{w}_{1}} \times \mathrm{d}_{2}$ 
Where:

$\mathrm{d}_{1}=$ is the Density we are looking for

$\mathrm{d}_{2}=$ is the density of water

$\mathrm{w}_{1}=$ weight of density bottle

$\mathrm{w}_{2}=$ weight of the density bottle + distill water

$\mathrm{w}_{3}=$ weight of the density bottle + Sample

\subsubsection{Viscosity measurements}

Capillary viscometers commonly measure the kinematic viscosity which is the ratio of viscosity to the density of a solution. The Ostwald viscometer was clamped to retort stand and dipped in to a $1000 \mathrm{~cm}^{3}$ beaker which was filled with water. The sample solutions and reference solvent were analyzed under a temperature controlled thermostatic bath. Samples were then inserted in to the viscometer by the use of pipette until the down loop was filled. Suction pump was used to absorb the sample from the down loop to high loop where the two marks are provided. The solution was released to flow from the top mark till it reached the lower mark, and the time of flow was recorded using digital stop watch at $30^{\circ} \mathrm{C}$, for each sample.

(Leo, Chem. Anal. Ed., 9 (2), 85-90, December 1937).

\subsubsection{Intrinsic viscosity calculations}

Viscosity of a solution containing even the slightest amount of a solute (polysaccharide), is always greater than that of a pure solvent. This is as a result of the larger size of the polysaccharide molecule as compared to that of the pure solvent. The viscosity determined using a capillary viscometer can be calculated using the equation below.

$\eta=A \rho t$

Where $\eta$ indicates viscosity, $\rho\left(\mathrm{g} / \mathrm{cm}^{3}\right)$ is the fluid density, A $\left(\mathrm{cm}^{2} / \mathrm{s}^{2}\right)$ is called instrumental constant of the viscometer, and $\mathrm{t}$ is the time of flow.

The relative viscosity of a solution is given by:

$\eta_{\mathrm{r}}=\eta_{\mathrm{s}} / \eta_{0}=\rho_{\mathrm{s}} \cdot \mathrm{t}_{\mathrm{s}} / \rho_{0} \cdot \mathrm{t}_{0}$

$\eta_{\mathrm{r}}$ is the relative viscosity, $\eta_{\mathrm{s}}$ is the viscosity of solution and $\eta_{\mathrm{o}}$ is the viscosity of solvent. $\rho_{\mathrm{s}}$ and $\rho_{\mathrm{o}}$ are the viscosities of solution and solvent respectively. Also $t_{s}$ and $t_{o}$ represent time of draining of solution and solvent respectively.

Specific viscosity or rather increment in relative viscosity is given by the equation below.

$\eta_{\mathrm{sp}}=\eta_{\mathrm{r}}-1$

Reduced viscosity is given by the first term of the Huggins equation.

$" \eta_{\text {red }}=\eta_{s p} / C$

In Huggins' method (Huggins, M. L. 1942.), intrinsic viscosity [ $\eta$ ] is defined as the ratio of the increase in relative viscosity ( $\left.\eta_{\mathrm{sp}}\right)$ to concentration ( $\mathrm{c}$ in $\mathrm{g} / \mathrm{cm} 3$ ) when the latter tends towards zero.

$\eta_{s p} / C=[\eta]+K_{H}[\eta]^{2} c$

Where $K_{H}$ is Huggins constant.

The Kraemer (Kraemer, E. O. 1938) propose the following equation:

$\ln \left(\eta_{r}\right) /_{c}=[\eta]+K_{K}[\eta]^{2} c$

Where $K_{K}$ is Huggins constant.

The Martin (Martin, A. F. 1942) proposes the following equation:

$\ln \left(\eta_{r} / C\right)=\ln [\eta]+K_{M}[\eta]^{2} c$

where $K_{M}$ is Martin's constant.

Fuoss (Fuoss, R. M. 1948) propose the following equation:

$C / \eta_{s p}=1 /[\eta]+K_{f s} 1 /[\eta] c^{1 / 2}$

Where $\mathrm{K}_{\mathrm{Fs}}$ is Fuoss constant.

Fedors (Fedors, R. F. 1979.) propose the following equation:

$\frac{1}{\eta_{r}^{1 / 2}-1}=\frac{1}{[\eta] c}-\frac{1}{[\eta] C_{\max }}$

Where $\mathrm{C}_{\max }$ is polymer parameter concentration.

Heller (Fedors, R. F. 1979.) propose the following equation: 
$\frac{1}{2} c\left(\frac{1}{\eta_{s p}}+\frac{1}{I n \eta_{r}}\right)=\frac{1}{[\eta]}-K_{H_{\mathrm{e}}}{ }^{c}$

Where $K_{H e}$ is Heller's constant.

Lyons \& Tobolsky (Lyons, P. F., Tobolsky, A. V. 1970; Quadrat, O. 1977) propose the following equation:

$\ln \frac{\eta_{s p}}{C}=\ln [\eta]+\left(\frac{K_{L-T}[\eta] c}{1-b c}\right)$

where $\mathrm{K}_{\mathrm{L}-\mathrm{T}}$ and $\mathrm{b}$ are constant

Baker (Baker, F. 1913 and Lewandowska, K. et al 2001) propose the following equation:

$\eta_{r}{ }^{1 / n}=1+[\eta]^{c} / n$

$n=\frac{1}{1-2 K_{H}}$

With $0.25<K_{H}<1$, and $K_{H}=0.9204$

Tager (Tager, A. 1978) propose the following equation:

$\eta_{r}{ }^{K_{B}} / \eta_{s p}=1 /[\eta]\left(K_{T 1}+K_{T 2} c^{2}\right)$

Where $K_{T 1}$ and $K_{T 1}$ are Tager's constant.

Budtov (Budtov, V. P. 1976) propose the following equation:

$\eta_{r}{ }^{K_{B}}=1+=1+K_{B}[\eta] c$

$K_{B}=1-2 K_{M}$

Where $K_{M}$ is Martin's constant. This method is not applicable to intrinsic viscosity and molecular weights as high and $K_{M}>0.5$. Solomon \& Gotesman (Solomon, O. F. et al 1967) propose the following equation:

$1+\frac{1}{3} \eta_{s p}=[\eta] \frac{\eta_{s p}}{C}$

Arrhenius-Rother-Hoffmann (Hoffmann, M. at el 1957) propose the following equation:

$\frac{\operatorname{In} \eta_{r}}{C}=[\eta]+K_{A} \ln \eta_{r}$

Where $\mathrm{K}_{\mathrm{A}}$ is constant.

Kreisa (Kreisa, J. at el 1960) propose the following equation:

$\frac{\eta_{s p}}{C}=[\eta]+K_{K r} \frac{\eta_{s p}^{2}}{C}$

Where $\mathrm{K}_{\mathrm{Kr}}$ is Kreisa's constant.

Staudinger \& Heuer (Hoffmann, M. 1957) propose the following equation:

$\operatorname{In}\left(\frac{\eta_{s p}}{C}\right)=\operatorname{In}[\eta]+K_{S-H}[\eta] C$

Where $\mathrm{Ks}_{\mathrm{s}-\mathrm{H}}$ is a constant.

Schramek [Schramek, W. 1955.] propose the following equation:

$\left(\frac{\eta_{s p}}{C}\right)^{1 / n}=[\eta]^{1 / n}+K_{S c h}{ }^{C}$

Where $\mathrm{K}_{\text {Sch }}$ is Schramek's constant.

This work proposes the following equation

$\left(\frac{\eta_{s p}}{C}\right)^{2}=[\eta]^{2}+K_{K r^{2}}\left(\frac{\eta_{s p}^{2}}{C}\right)^{2}$

Where $K_{K r}$ is Kreaser's constant

\subsubsection{Critical concentration}

The critical concentration $C_{*}$ is calculated using the formula below

$C_{*} \approx \frac{1}{[\eta]}$ 
At $C_{*}>\frac{1}{[\eta]}$, the flow behavior is governed by intermolecular interactions of the polymer coils; while at $C_{*}<\frac{1}{[\eta]}$, the interaction is dominated mainly by the polymer-solvent interactions.

\subsubsection{Molecular weight}

Mark-Houwink-Sekurada equation was used to calculate the viscosity average molecular weight of the gum. This equation relates the intrinsic viscosity of the gum $[\eta]$, and the average molecular weight. The equation is given by

$[\eta]=K M^{a}$

' $\mathrm{K}$ ' and ' $\mathrm{a}$ ' are constants called the MHS parameters. These parameters are specific for a particular polymer and solvent, and at a particular temperature. The exponent 'a', is a measure of solvent quality. It is also related to structure, orientation and flexibility of polymer bonds. (Kulicke and Clasen 2004; Picout and Ross-Murphy 2007). From the MHS equation, the intrinsic viscosity values can be plotted on a logarithmic scale as a function of the logarithm of the molecular weight to obtain a straight line with slope equal to 'a'.

\section{Results and discussion}

\subsection{Acetylation of gum Arabic}

Acetic anhydride, acetic acid or even vinyl acetate are used in the modification of starches to produce starch acetates. During the reaction process, hydroxyl groups on the glucose units are replaced with acetyl groups to form esters. Certain factors like reactant concentration, time of reaction, catalyst and $\mathrm{pH}$ determine the number of acetyl groups formed in the starch matrix. (Durdica et al., 2015). In this project acetic anhydride is used instead of acetic acid. This is because acetic acid is a weak acid and its reaction with starch hydroxyl groups is reversible and the equilibrium constant does not favor the product side. The reaction is represented below<smiles>OCC1(CO)C(O)C(O)C(O)C1O</smiles><smiles>CC(=O)OC(C)=O</smiles><smiles>CC(=O)CC1(CO)OC(O)C(O)C(O)C1O</smiles><smiles>CC(=O)O</smiles>

\subsection{FTIR}

Fig. 1 and 2 shows the FTIR of pure and acetylated gum arabic. The spectra of acetylated gum show the processing of new peak around $750 \mathrm{~cm}^{-1}$ to $700 \mathrm{~cm}^{-1}$ attributed to $\operatorname{COOR}$ stretching indicating the presence of an ester. The peak is seen to be absent in the native gum

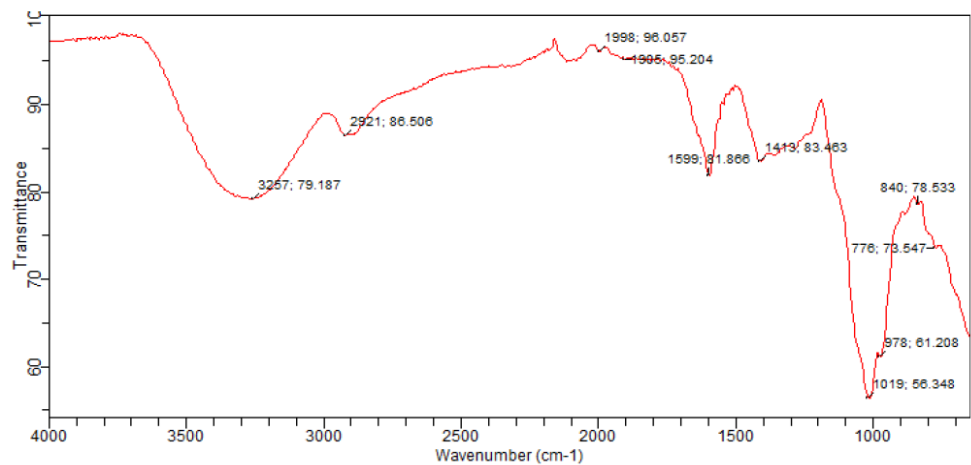

Fig. 1: Ftir Spectra of Pure Gum Arabic.

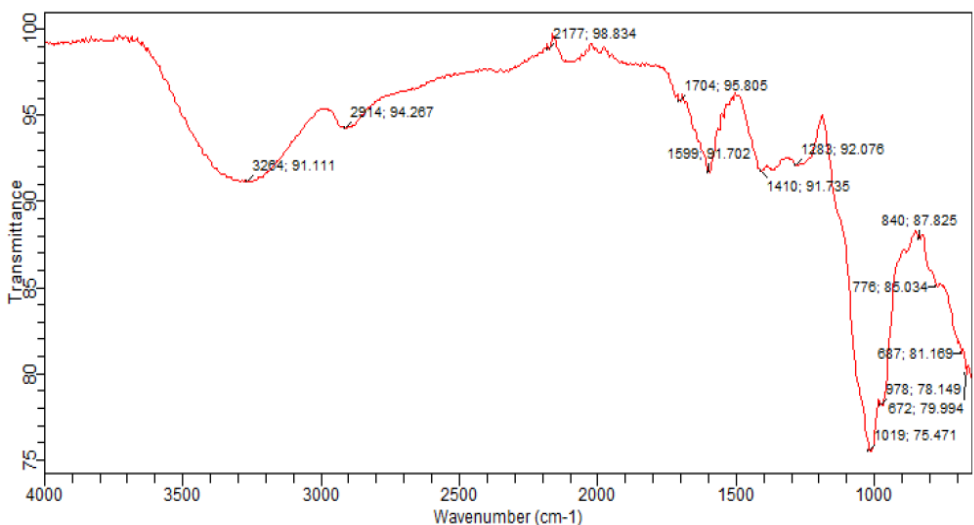

Fig. 2: Fitr Spectra of Acetylated Gum Arabic. 


\subsection{Densities}

Fig. 3 compares densities of pure and acetylated gum samples at different concentrations. The trend shows at all concentrations, modified gum sample has a higher density compared to the pure sample.

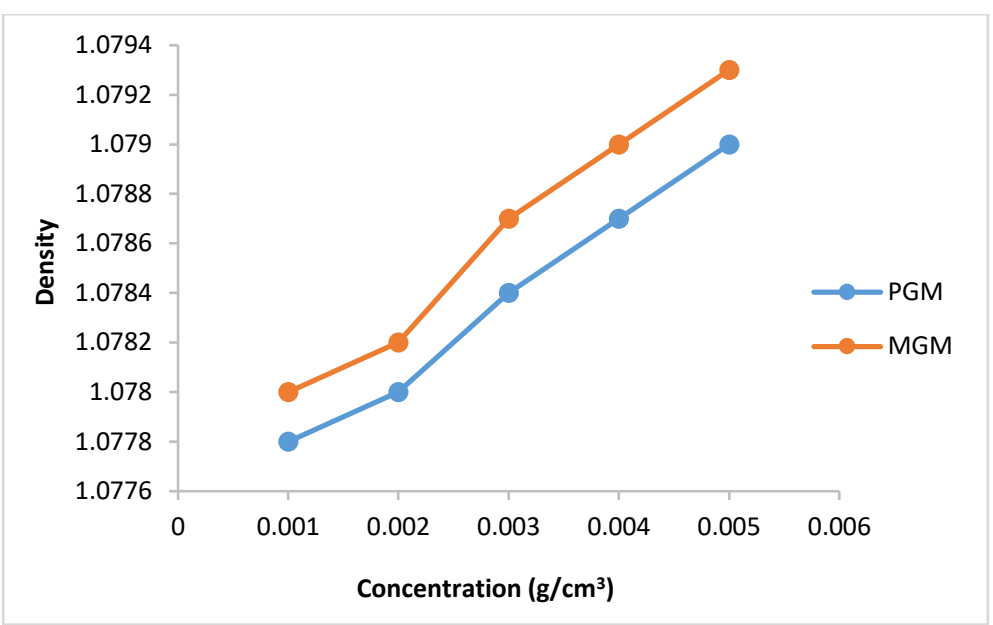

Fig. 3: Densities of Pure and Modified Gum Arabic.

\subsection{Relative viscosity}

In relative viscosity, the viscosity of the solute solution is determined relative to that of the solvent. Then from their mathematical relationship a lot of polymer parameters can be calculated. The relative viscosity of pure and acetylated gum Arabic is presented in fig 4 . From the figure, it is seen that relative viscosity of acetylated gum Arabic is greater than that of pure gum Arabic. This however, does not agree with the findings of Muhamedbegović et al. (2012), who worked on acetylation of potato starch. In their work, they found a decrease in viscosity after acetylation of the starch. Berski et al. (2011) made similar observation when they acetylated Oat starch. Saartrat et al. (2005) also observed same trend after acetylation of Canna starch. The relative viscosity of acetylated starch is dependent on the uniformity of acetylation. That is whether the acetylation reached the inner lamellae of granules or just restricted to its outer part (Huang et al. 2007). According to Saartrat et al. (2005), the relative viscosity of starches could either decrease or increase after acetylation. This is due to the disruption of either inter or intra molecular bonds during the acetylation process.

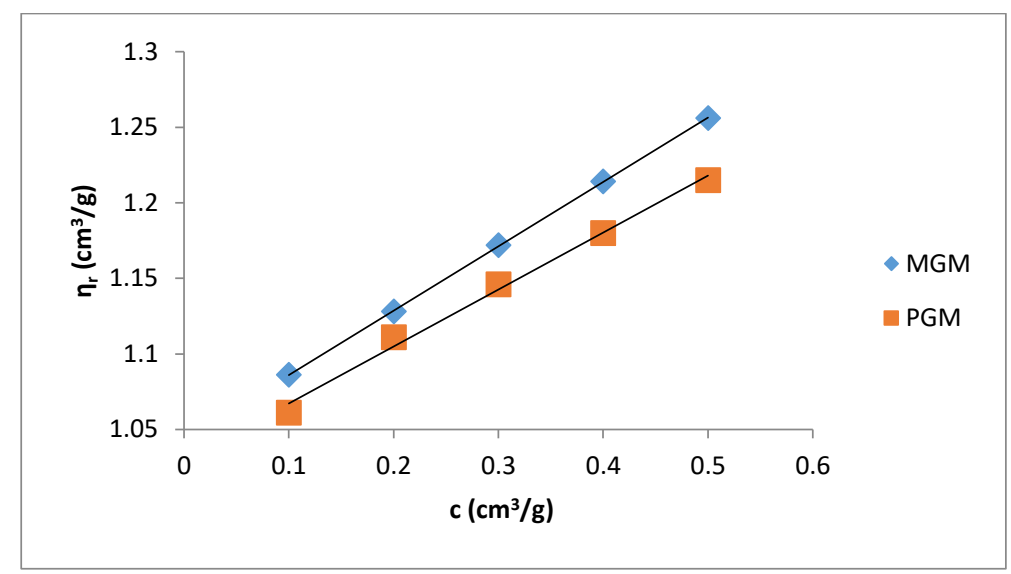

Fig. 4: Relative Viscosities of Pure and Acetylated Gum Arabic.

\subsection{Intrinsic viscosity}

Intrinsic viscosity is the contribution of individual molecules to the viscosity of a solution. It gives insight into polymer shape, structure, molecular weight and other hydrodynamic parameters. In this work, multi-concentration viscosity measurement approach was used, and therefore, several solutions were prepared with different gum concentrations (Nicholson, 2017). The intrinsic viscosity of pure and acetylated gum Arabic is determined using different plot methods. Table 1 shows the intrinsic viscosity of pure gum Arabic. The value differs considerably with that reported by Anderson and Rahma (1967).). This might be attributed to difference in geographic location of the parent tree, or due to difference in purification methods. However, the intrinsic viscosity falls within the range reported by Renard et al., (2006) and Yebeyen et al., (2009). Taking the Huggins plot as standard, the intrinsic viscosity was determined from the plot of reduced viscosity as a function of concentration. Those plots that have relative errors (RE) less than 5\% are considered feasible and comparable to Huggin's method. Those methods with RE greater than 5\% are considered poor and not comparable to Huggin's method. The results in table 1 shows Kreamer (RE 2.4\%), Martin (RE 1.3\%), Lyon-Toblosky (RE 2.12\%), Staudinger-Heuer (RE 2.12\%), Maron-Reznik (RE $3.46 \%$ ) and our proposed method (RE $1.85 \%$ ), are good and comparable to Huggins method. 
Table 1: Intrinsic Viscosities of Modified Gum Arabic Using Different Plot Methods

\begin{tabular}{|c|c|c|c|c|c|c|}
\hline Method & Huggins & Kraemer & Martin & Fuoss & Fedors & Arrhenius-Rother-Hoffmann \\
\hline$[\eta]\left(\mathrm{cm}^{3} / \mathrm{g}\right)$ & 86.43 & 83.59 & 88.28 & 80 & 106.38 & 95.033 \\
\hline $\mathbf{R}^{2}$ & 0.8120 & 0.8354 & 0.8619 & 0.7943 & 0.9807 & 0.8479 \\
\hline RE\% & - & 3.29 & 2.14 & 7.44 & 23.08 & 9.95 \\
\hline Method & Heller & Lyon-Tobolsky & Tager & Budtov & Maron-Reznik & Kreisa \\
\hline$[\eta]\left(\mathrm{cm}^{3} / \mathrm{g}\right)$ & 92.59 & 87.9 & 63.29 & 66.07 & 83.25 & 112.95 \\
\hline $\mathbf{R}^{2}$ & 0.8170 & 0.8606 & 0.9015 & 0.997 & 0.7745 & 0.7058 \\
\hline RE\% & 7.13 & 1.7 & 26.77 & 23.56 & 3.68 & 30.7 \\
\hline Method & Staudinger-Heuer & Square & Square Root & Mean & Proposed Method & \\
\hline$[\eta]\left(\mathrm{cm}^{3} / \mathrm{g}\right)$ & 87.89 & 75.92 & 114.06 & 45.43 & 85.45 & \\
\hline $\mathbf{R}^{2}$ & 0.8606 & 0.5945 & 0.9075 & 0.8477 & 0.5898 & \\
\hline RE\% & 1.7 & 12.16 & 31.97 & 47.43 & 1.13 & \\
\hline
\end{tabular}

Table 2: Intrinsic Viscosities of Pure Gum Arabic Using Different Plot Methods

\begin{tabular}{|c|c|c|c|c|c|c|}
\hline Method & Huggins & Kraemer & Martin & Fuoss & Fedors & Arrhenius-Rother-Hoffmann \\
\hline$[\eta]\left(\mathrm{cm}^{3} / \mathrm{g}\right)$ & 64.59 & 63.04 & 65.43 & 100 & 68.96 & 68.23 \\
\hline $\mathbf{R}^{2}$ & 0.9615 & 0.9635 & 0.9717 & 0.9767 & 0.9807 & 0.9815 \\
\hline RE\% & - & 2.40 & 1.3 & 54.8 & 6.76 & 5.64 \\
\hline Method & Heller & Lyon-tobolsky & Tager & Budtov & Maron-Reznik & Kreisa \\
\hline$[\eta]\left(\mathrm{cm}^{3} / \mathrm{g}\right)$ & 64.9 & 65.96 & 59.17 & 53.95 & 62.35 & 74.536 \\
\hline $\mathbf{R}^{2}$ & 0.9878 & 0.9706 & 0.8506 & 0.9984 & 0.9219 & 0.9537 \\
\hline RE\% & 0.48 & 2.12 & 8.39 & 16.47 & 3.46 & 15.4 \\
\hline Method & Staudinger-Heuer & Square & Square Root & Mean & Proposed Method & \\
\hline$[\eta]\left(\mathrm{cm}^{3} / \mathrm{g}\right)$ & 65.96 & 58.46 & 79 & 32.57 & 63.40 & \\
\hline $\mathbf{R}^{2}$ & 0.8606 & 0.8302 & 0.9848 & 0.9775 & 0.9374 & \\
\hline RE\% & 2.12 & 9.49 & 21.8 & 49.57 & 1.84 & \\
\hline
\end{tabular}

In table 2, the acetylated gum Arabic shows a higher intrinsic viscosity than the native gum. The viscosity of acetylated gum is 86.43 which is higher than that of pure gum (63.40). This could be due to increase in swelling power of the acetylated gum. Acetylation also increases emulsifying ability of gums, thereby increasing the viscosity, (Samia et al., 2009). Introduction of acetyl groups also reduces bond strength between gum molecules and thereby increasing swelling and solubility of the molecules. This enhances access of water to amorphous areas, increasing water holding capacity of the gum matrix and developing a more organised structure leading to a higher resistance to deformation and achieving a higher peak viscosity (Hovers and Susulski, 1985). Other methods were also used to find the intrinsic viscosity. The ones that were most comparable to Huggins and have lower RE values are; Kreamer (RE 3.29\%), Martin (RE 2.14\%), Lyon-Tobolski (RE 1.7\%), Staudinger-Heuer (RE 1.7\%), Maron and Reznik (3.68\%) and our proposed method (RE 4.10\%). The rest have RE values greater than $5 \%$ and are considered not comparable to Huggins.

It was observed that not all methods that are comparable to Huggins fitted the two samples well. Heller's method stands out here. It was comparable to Huggins method in the pure gum sample with a relative error of $0.48 \%$, but in the acetylated sample, it became a poor method with a RE of 7.13\%. It is still not clear why this happened, but it could be due to the correlation of data between the two samples. In almost all plots used, the native gum has higher correlation than the acetylated gum. This could make some plots agreeable to Huggin's in the native while not agreeable to Huggin's in the acetylated sample.

The Kreiser method which this work modifies gave a very high relative error of $15.4 \%$ and $30.7 \%$ in pure and acetylated samples respectively. The method proposed herein is modification of the Kreiser method and has fitted well and is comparable to Huggins method in both samples with RE values of 1.84 and $1.13 \%$ for pure and acetylated gum respectively.

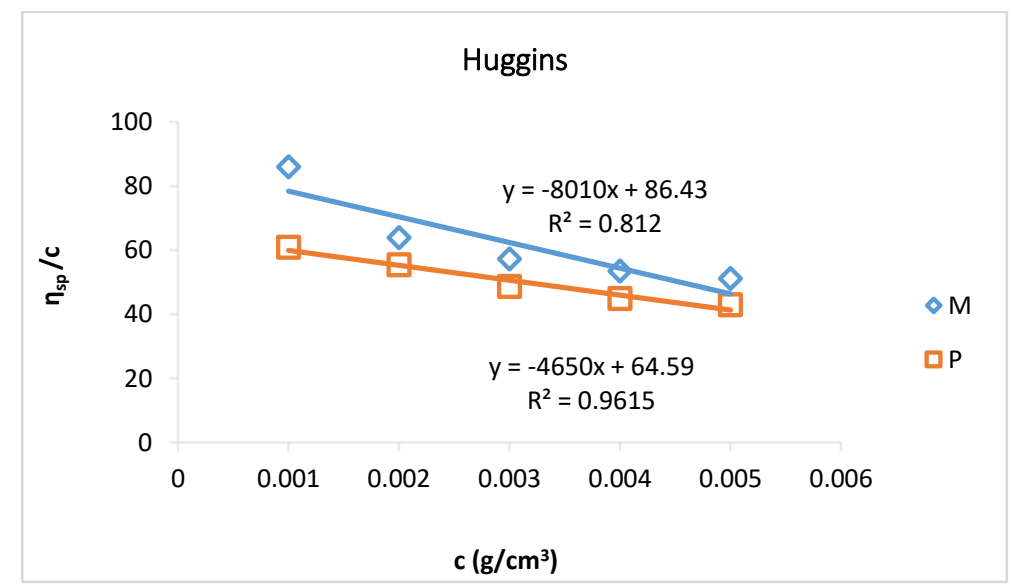

Fig. 5: Huggin's Method. 


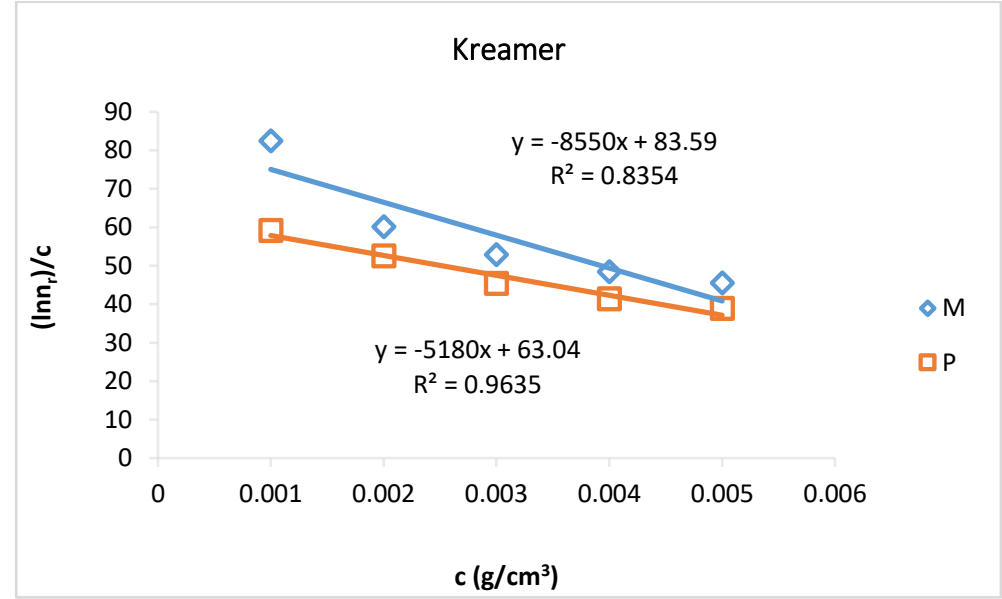

Fig. 6: Kreamer Method.

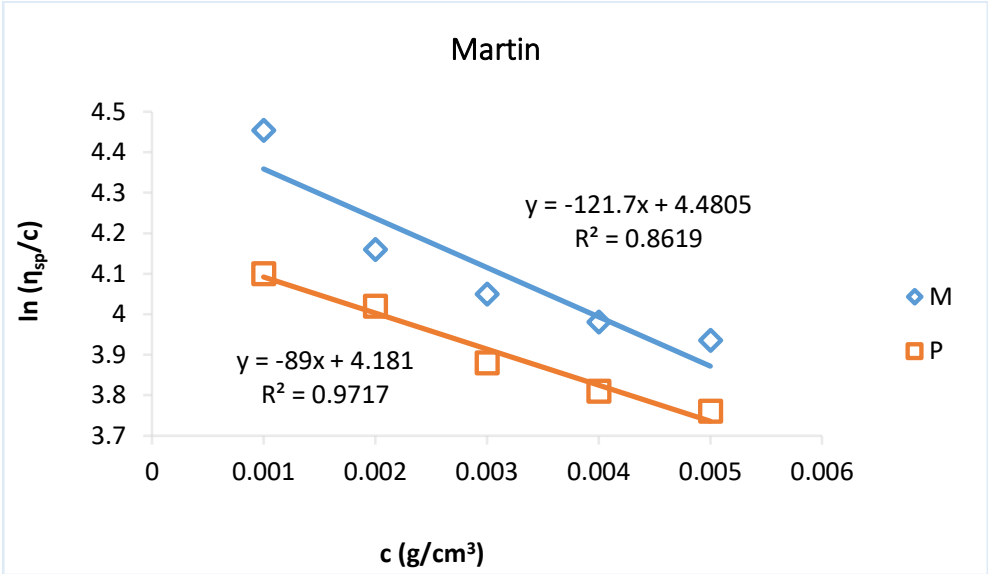

Fig. 7: Martin Method.

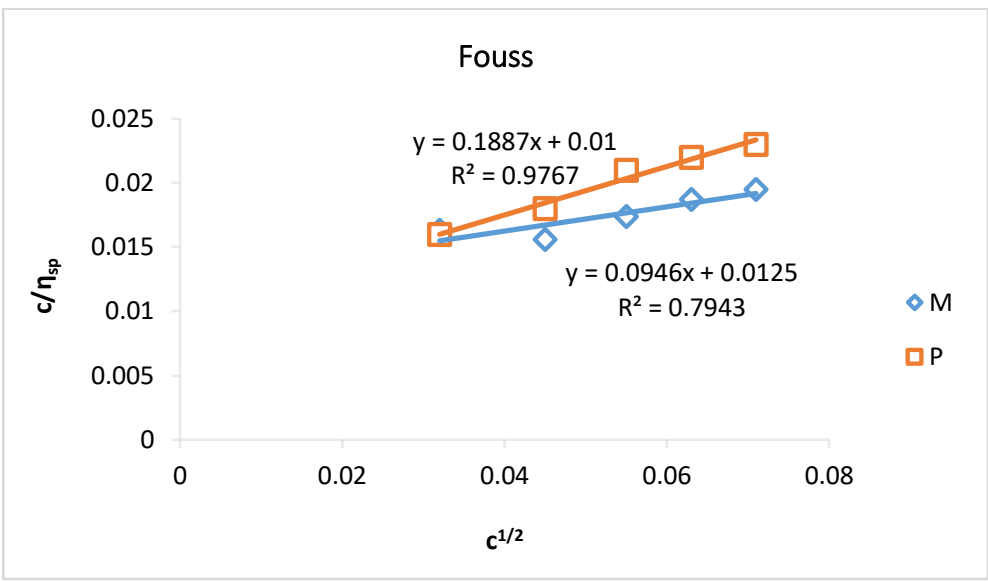

Fig. 8: Fouss Method.

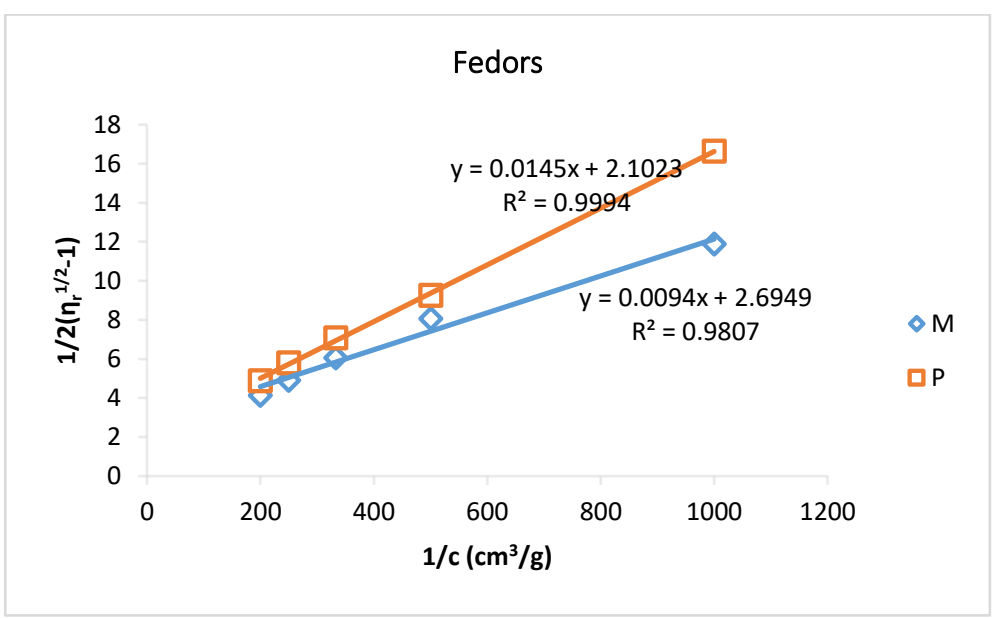


Fig. 9: Fedors Method.

Heller

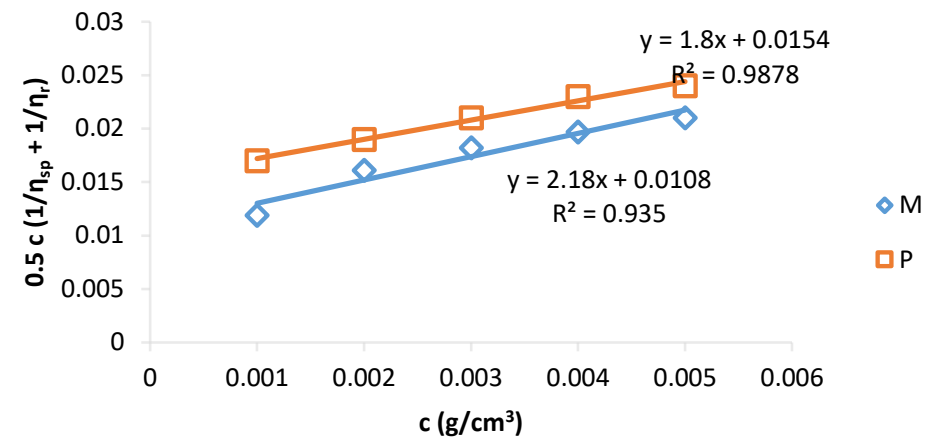

Fig. 10: Heller Method.

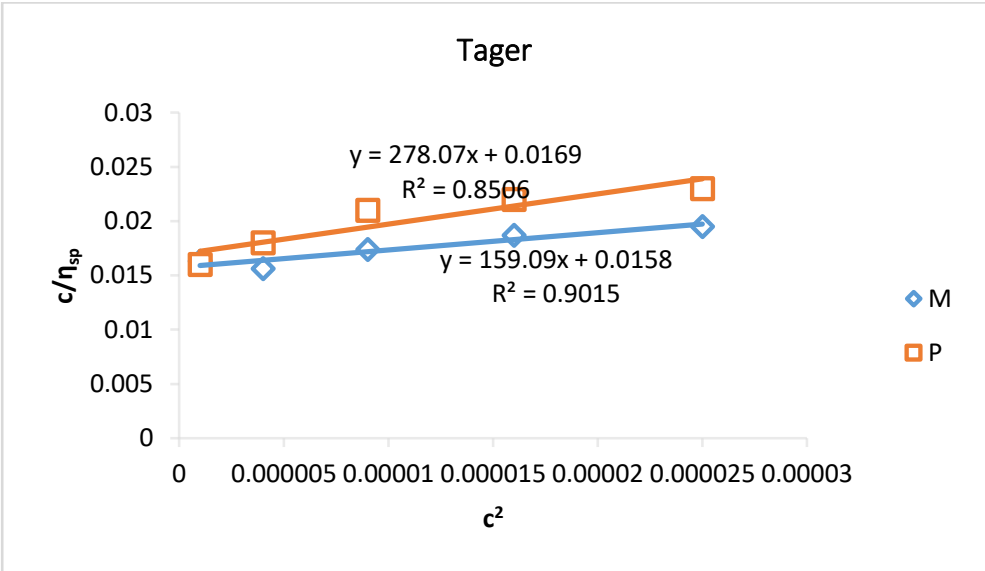

Fig. 11: Tager Method.

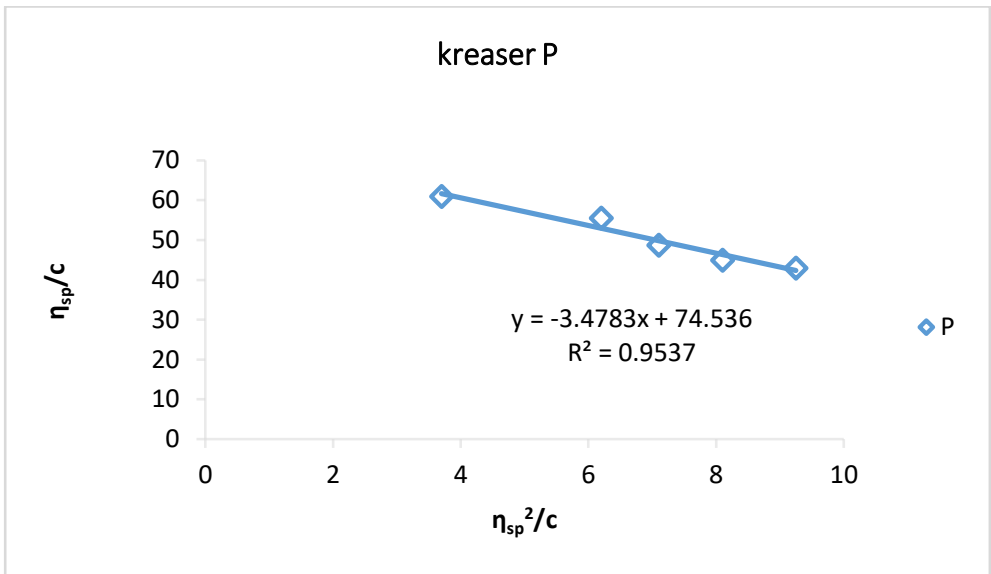

Fig. 12: Kreaser Method for Pure Gum Arabic (P)

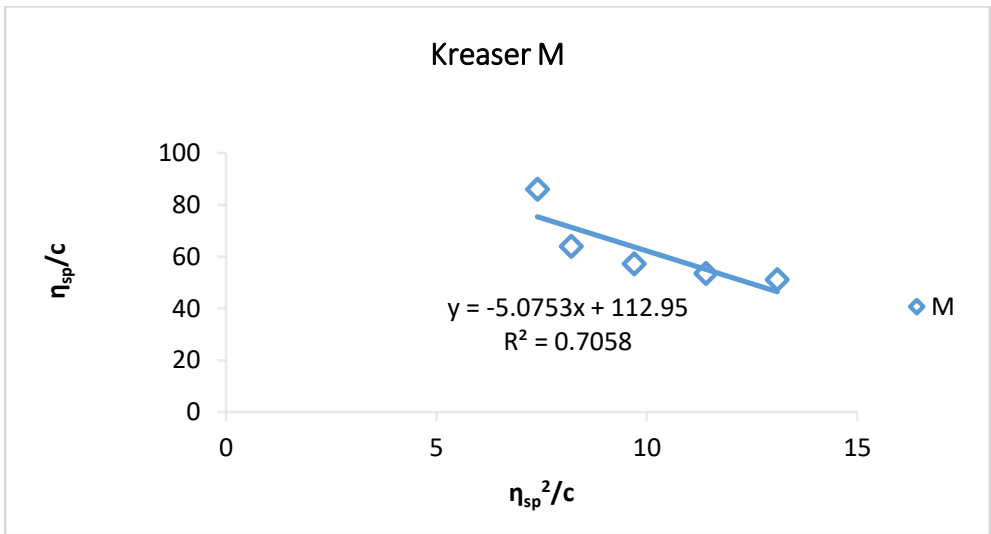

Fig. 13: Kreaser Method for Modified Gum Arabic (M) 


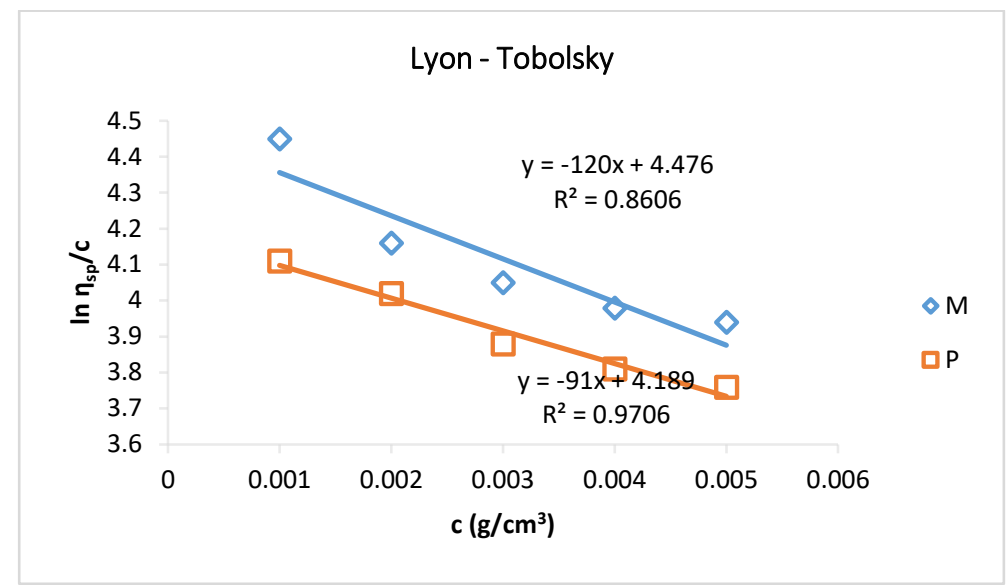

Fig. 14: Lyon - Tobolsky Method.

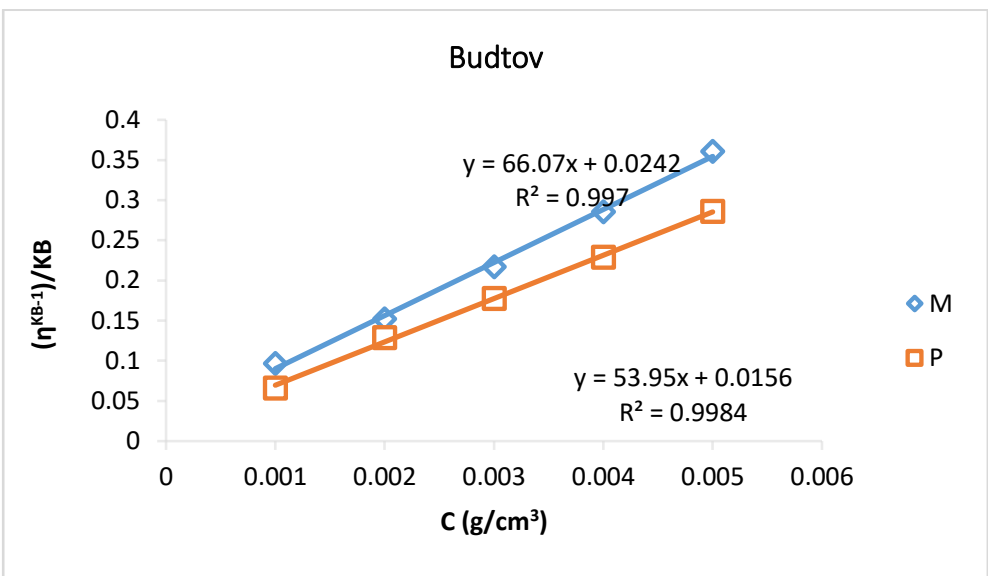

Fig. 15: Budtov Method.

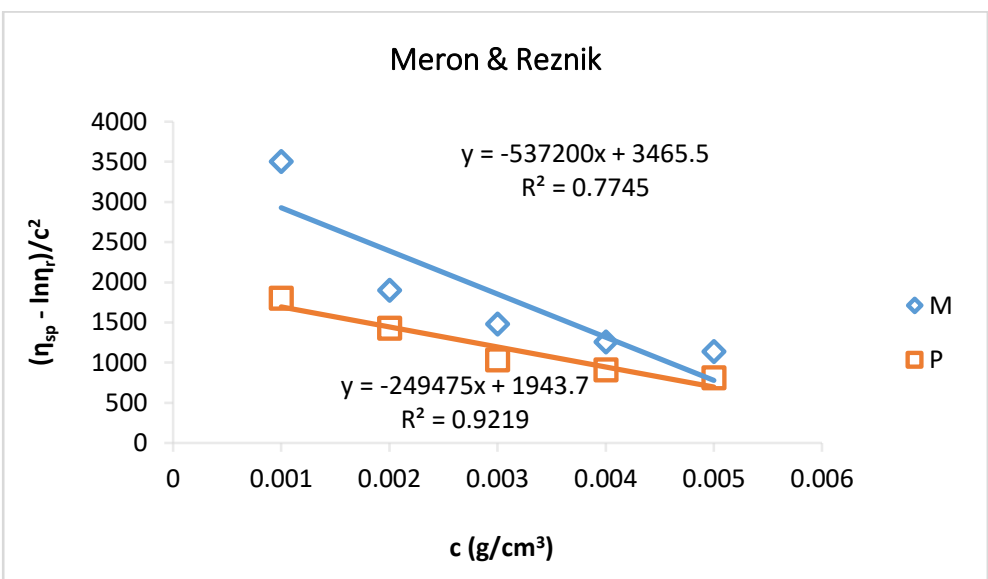

Fig. 16: Meron and Reznik Method.

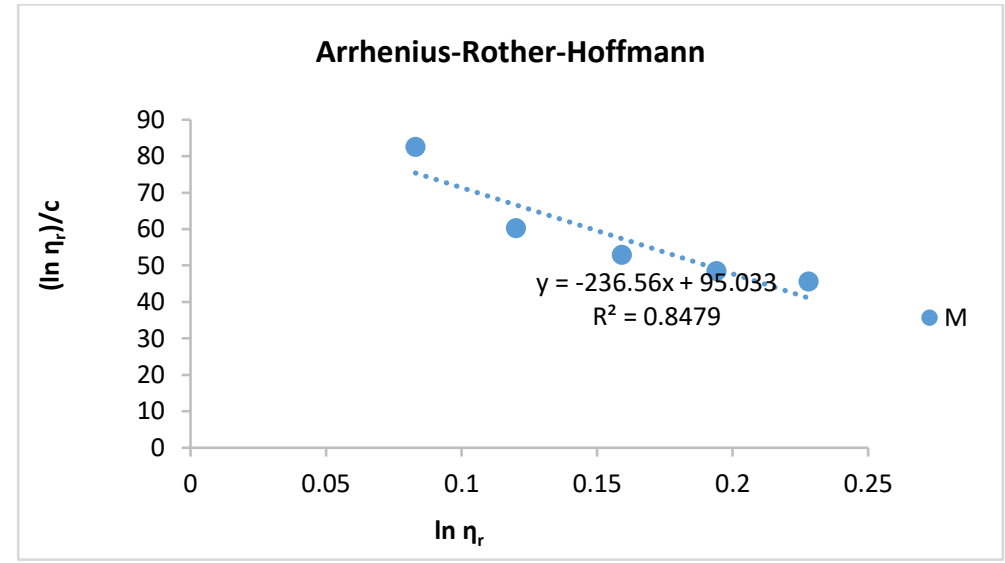

Fig. 17: ARH Method for Modified Gum Arabic (M). 


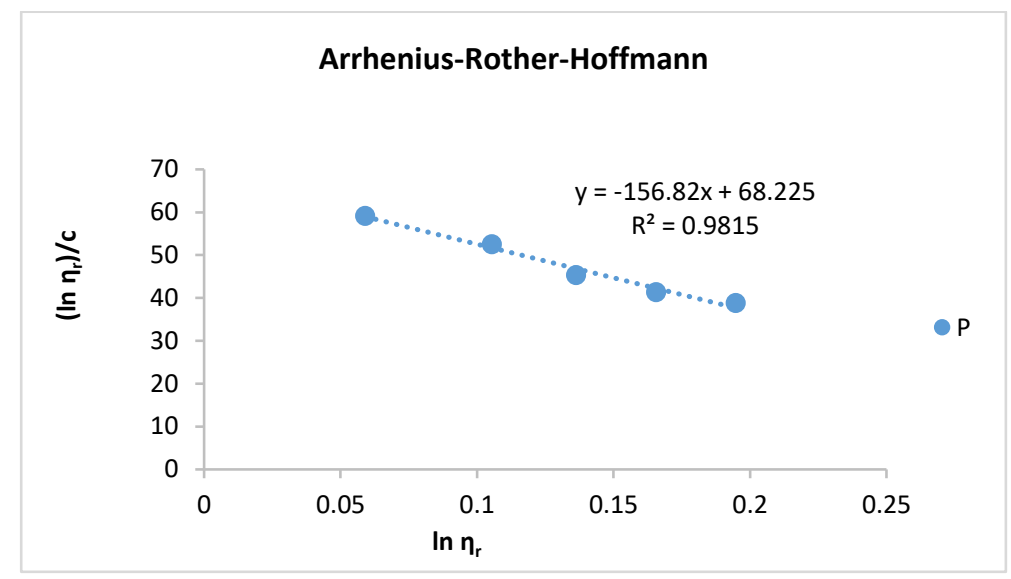

Fig. 18: ARH Method for Pure Gum Arabic (P)

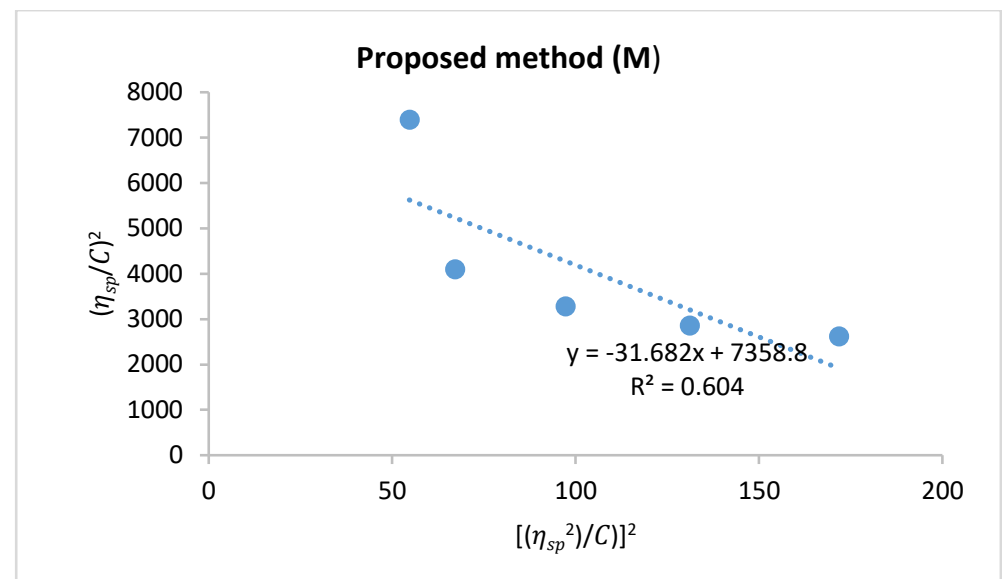

Fig. 19: Proposed Method for Modified Gum (M).

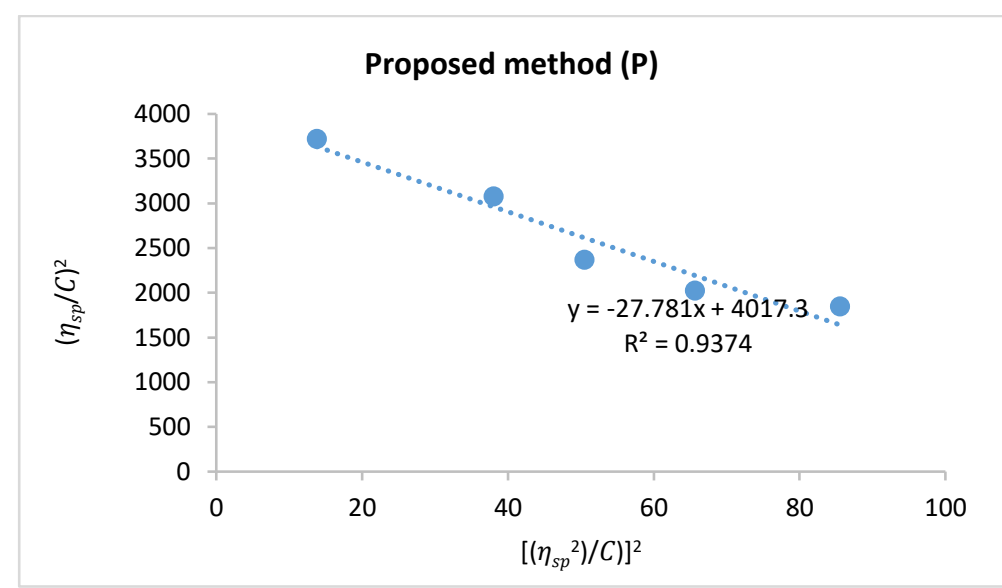

Fig. 20: Proposed Method for Pure Gum (P).

\subsection{Molecular weight determination}

The molecular weight is important in determining functional characteristics of polymers such as strength and processing ability. The viscosity average molecular weight of native gum arabic found from this study is $8.64 \times 10^{6} \mathrm{gmol}^{-1}$ which is greater than most gums such as xanthan gum $\left(4.05 \times 10^{6} \mathrm{gmol}^{-1}\right)$, guar gum $\left(1.45 \times 10^{6} \mathrm{gmol}^{-1}\right)$, gellan gum $\left(1.64 \times 10^{6} \mathrm{gmol}^{-1}\right)$ and locust been gum $\left(1.6 \times 10^{6} \mathrm{gmol}^{-1}\right)$ (Fatemeh et al, 2018). The molecular weight of acetylated gum Arabic was found to be $14.9 \times 10^{6} \mathrm{gmol}^{-1}$ which is greater than that of native gum. This could be due to the substitution of hydroxyl groups with a larger ester group in the modified gum which in turn increases its solubility (Samia et al, 2009). Similar observation was made by Adeyanju et al., (2016). They found that chemical modification of polysaccharides produces products with improved physicochemical and functional properties that are not available from commercial polysaccharides. They acetylated Sweitenia mycropylla gum with acetic anhydride in the presence of sodium hydroxide. The result they found showed that acetylated gum had higher values of solubility, viscosity and swelling index.

\subsection{Critical concentration}

The critical concentration $\left(\boldsymbol{c}^{*}\right)$ is calculated from equation (21). The value for pure gum arabic was found to be $0.0155 \mathrm{~g} / \mathrm{cm}^{3}$ and that of acetylated gum Arabic was found to be $0.01157 \mathrm{~g} / \mathrm{cm}^{3}$. All these values are above the maximum concentration of gum samples $\left(0.005 \mathrm{~g} / \mathrm{cm}^{3}\right)$. This indicates, the solutions are Newtonian and there are no entanglements between the molecules. Also it shows the viscosity determined was purely based on molecule-solvent interaction. 


\section{Conclusion}

This work showed that the modified gum has a higher density than the pure gum, and as a result, relative viscosities and intrinsic viscosities were found to be greater in the modified gum. Also, from the different plots made, not all fitted well in calculating an accurate intrinsic viscosity for both samples. Some fitted well in the modified sample, and not that well into the pure sample. This work's modification of the Kreiser method gave an intrinsic viscosity that is comparable to the Huggin's method in both samples. The relative error calculated for our modified Kreiser method in far below that of the proper Kreiser method. This makes the proposed method viable. Also on comparing the molecular weights for the two samples, it was observed that the modified sample has a higher molecular weight which could be due the presence of bulkier ester groups.

\section{References}

[1] Baker, F. (1913). The Viscosity of Cellulose Nitrate Solutions. Journal of the Chemical Society 103, $1653-1675$. https://doi.org/10.1039/CT9130301653.

[2] Baldwin, T. C., Quah, P. E., Menzies A. R., A serotaxonomic study of Acacia gum exudates. Phytochemistry, 50, 599-606, February 1999. https://doi.org/10.1016/S0031-9422(98)00594-9.

[3] Ben-Zion, O., Nussinovitch, A., Physical properties of hydrocolloid wet glues. Food Hydrocolloids, 11 (4), 429-442, October 1997. https://doi.org/10.1016/S0268-005X(97)80041-0.

[4] Berski, W.; Ptaszek, A.; Ptaszek, P.; Ziobro, R.; Kowalski, G.; Grzesik, M.; Achremowicz, B. Pasting and rheological properties of oat starch and its derivatives. Carbohydr. Polym. 2011, 83, 665-671. https://doi.org/10.1016/j.carbpol.2010.08.036.

[5] Beyer, M., Reichert, J., Heurich, E., Jandta, K., D., Sigusch, B.W., Pectin, alginate and gum arabic polymers reduce citric acid erosion effects on human enamel. Dental Materials, 26 (9), 831-839, April 2010. https://doi.org/10.1016/j.dental.2010.04.008.

[6] Budtov, V. P. (1976). Generalized concentration dependence of the viscosity of concentrated polymer solutions. Polymer Mechanics, 12, 1, 151-154. Translated from Mekhanika Polimerov, 1, 172-175, 1974. https://doi.org/10.1007/BF00857219.

[7] Cochrane, H., Adhesives and sealants. Industrial Minerals and Their Uses, 1996, 275-352 https://doi.org/10.1016/B978-081551408-4.50008-9.

[8] Dickinson, Eric. Hydrocolloids at interfaces and the influence on the properties of dispersed systems. Food Hydrocolloids, 17, 25-39 January 2003. https://doi.org/10.1016/S0268-005X(01)00120-5.

[9] Fedos R. F., (1979), An equation suitable for describing the viscosity of dilute to moderate concentrated polymer solutions. Polymer vol $20 \mathrm{pp} 225-$ 228 https://doi.org/10.1016/0032-3861(79)90226-X

[10] Fouss R. M (1948) Viscosity function for polyelectrolytes. J polymer Sci. vol 3, pp 603-604 https://doi.org/10.1002/pol.1948.120030414.

[11] Gilcksman M. and Sand R. E. (1973), "Gum Arabic; Industrial Gum Polysaccharides and their Derivatives", Academic Press, New York. https://doi.org/10.1016/B978-0-12-746252-3.50015-0.

[12] Heller, W. 1954. Treatment of Viscosity Data on Polymer Solutions (an Analysis of Equations and Procedures). I. Intrinsic Viscosity and Limiting Slope Constants. Journal of Colloid Science 9, 6, 547-573. https://doi.org/10.1016/0095-8522(54)90057-4.

[13] Hoover R. Y, Susulski F, (1985). A Comparative Study of the effect of acetylation on Starches of Phaseolus Vulgaris biotype. Starch/Starke 12: 397- 404. https://doi.org/10.1002/star.19850371202

[14] Huang, X., Kakuda, Y., Cui, W., Hydrocolloids in emulsions: particle size distribution and interfacial activity. Food Hydrocolloids, 15, 533-42, July 2001. https://doi.org/10.1016/S0268-005X(01)00091-1.

[15] Huggins, M. L. (1942). "The Viscosity of Dilute Solutions of Long-Chain Molecules. IV. Dependence on Concentration." Journal of American Chemical Society, 64 2716-2718. https://doi.org/10.1021/ja01263a056.

[16] Islam, A. M., Phillips, G. O., Sljivo, A., Snowden, M. J., Williams, P.A., A review of recent developments on the regulatory, structural and functional aspects of gum arabic. Food Hydrocolloids, 11 (4), 493-505, May 1997. https://doi.org/10.1016/S0268-005X(97)80048-3.

[17] Kreamer, E. O., (1938), molecular weights of cellulose and cellulose derivatives. Ind. Eng. Chem. Vol 30, pp 1200-1204 https://doi.org/10.1021/ie50346a023.

[18] Kreisa, J. (1960). J. Colloid. Czechosl. Chem. Commun. 25, 1507. https://doi.org/10.1135/cccc19601507.

[19] Kulicke, W. -M., and Clasen, C. (2004). Viscosimetry of Polymers and Polyelectrolytes. Springer Laboratory, https://doi.org/10.1007/978-3-66210796-6 4.

[20] Lewandowska, K., Staszewska, D. U., \& Bohdanecký, M. (2001). The Huggins viscosity coefficient of aqueous solution of poly (vinyl alcohol). European polymer journal, 37(1), 25-32. https://doi.org/10.1016/S0014-3057(00)00074-4.

[21] Lovell, P. A. (1989). "Dilute Solution Viscometry." Comprehensive Polymer Science and Supplements, Editor-in-Chief: Sir Geoffrey Allen, ed., Pergamon Press, Amsterdam, 173-197. https://doi.org/10.1016/B978-0-08-096701-1.00009-4.

[22] Lyons, P. F., Tobolsky, A. V. 1970. Viscosity of Polypropylene Oxide Solutions over the Entire Concentration Range. Polymer Engineering and Science, January, 70, 1, 1-3. https://doi.org/10.1002/pen.760100102.

[23] Maron, S. H., \& Reznik, R. B. (1969). A new method for determination of intrinsic viscosity. Journal of Polymer Science Part A-2: Polymer Physics, 7(2), 309-324. https://doi.org/10.1002/pol.1969.160070206.

[24] Martin, A. F (1942), Abstr. 133 and Am. Chem. Soc. Meeting, P 1 ACS

[25] Muhamedbegović, B.; Šubarić, D.; Babić, J.; Ačkar, Đ.; Jašić, M.; Keran, H.; Budimlić, A.; Matas, I. Modification of potato starch. Technol. Acta $2012,5,1-6$.

[26] Nasir, O., Artun, F., Wang, K., Rexhepaj, R., Föller, M., Ebrahim, A., Kempe, D. S., Biswas, R., Bhandaru, M., Walter, M., Mohebbi, N., Wagner, C. A., Saeed, A. M., Lang, F., Downregulation of Mouse Intestinal Na+-coupled Glucose Transporter SGLT1 by Gum Arabic (Acacia Senegal). Cell Physiol. Biochem., 25, 203-210, March 2010 https://doi.org/10.1159/000276554.

[27] Nicholson J. (2017), 'The Chemistry of Polymers' $5^{\text {th }}$ edition, Croydon, CPI Group.

[28] Oluyemsis A. B., Vivek R. S., Ruchita K and Oluwatoyin A. O, (2010) "Characterization and Evaluation of Terminalia randii gum as a Binder in Carvedilol Tablet Formulation", Acta pharmaceutica scienticia 52: 254-262.

[29] Quadrat, O. 1977. Dependence of viscosity on the concentration of polymer solutions. Use of the Lyons-Tobolsky equation. Collect. Czech. Chem. Commun. 42, 1520-1528. https://doi.org/10.1135/cccc19771520.

[30] Randall, R. C., Phillips, G. O., Williams, P. A. (1989), "Fractionation and characterization of gum from acacia Senegal", Food Hydrocolloids, 3, 6575 https://doi.org/10.1016/S0268-005X(89)80034-7.

[31] Renard, D., Robert, P., Lavenant, L., Melcion, D., Popineau, Y., Gueguen, J., Duclairoir, C., Nakache, E., Sanchez, C., Schmitt, C. Biopolymeric colloidal carriers for encapsulation or controlled release applications. International Journal of Pharmaceutics, 242, 163-166, August 2002. https://doi.org/10.1016/S0378-5173(02)00143-6.

[32] Sakai, T. (1968). "Huggins constant k' for flexible chain polymers." Journal of Polymer Science -- Polymer Physics Part A-2, 6(8), 1535-1549. https://doi.org/10.1002/pol.1968.160060810.

[33] Samia E. A, Babitar E. M, and Karamalla A., (2009). Analytical studies on Gum exudates of Anogeissus leiocarpus. Pakistan Nutrition 8(6): $782-$ 786 https://doi.org/10.3923/pjn.2009.782.786.

[34] Savary, G., Hucher, N., Bernadi, E., Grisel, M., Malhiac C., Relationship between the emulsifying properties of Acacia gums and the retention and diffusion of aroma compounds. Food Hydrocolloids, 24,178-183, September 2009. https://doi.org/10.1016/j.foodhyd.2009.09.003. 
[35] Sawunmi, Samuel (1990) 'Modification of gum Arabic ', Thesis submitted to department of chemical engineering, Ahmadu Bello University, Zaria.

[36] Schramek, W. (1955). Über eine neue viskositätsfunktion von weitem gültigkeitsbereich. II. Mitteilung über den physikalischen zustand und das physikalisch-chemische verhalten hochmolekularer stoffe. Die Makromolekulare Chemie: Macromolecular Chemistry and Physics, 17, 1, 19-28. https://doi.org/10.1002/macp.1955.020170102.

[37] Smolinske, S. C. (1992), "Handbook of Food, Drug and Cosmetic Excipients", Published by CRC Press LLC, Florida, USA. pp.

[38] Solomon, O. F., Gotesman, B. S. (1967). Calculation of viscosity number from a single measurement. Makromolek. Chem. 104, 177. https://doi.org/10.1002/macp.1967.021040119

[39] Staudinger H, and W. Heuer. (1934). Über hochpolymere Verbindungen. Z. Physik. Chem., 171 A, 129-180. https://doi.org/10.1515/zpch-193417113.

[40] Tager, A. (1978). The Physical Chemistry of Polymers, third ed. [in Russian], Khimiya, Moscow p. 544.

[41] Williams, P. A. (2000), "Handbook of Hydrocolloids", Published by Woodhead Publishing Ltd, Cambridge, London. Pp. 155-159. 